\title{
Visibilidade e invisibilidade: interseções literárias do feminino na Bíblia
}

\author{
Visibility and invisibility: literary intersections of the
}

feminine in the Bible

LUÍSA MARIA ALMENDRA ${ }^{a}$

\section{Resumo}

Este artigo procura uma abordagem da questão da visibilidade e invisibilidade do feminino na Bíblia, procurando debater os diferentes matizes que lhe são inerentes. Procura-se uma verdade e uma redescoberta da estratégia literária bíblica que seja integradora e ampla. $O$ debate supõe conhecer algumas notas prévias e a fragilidade de algumas formulações convencionais. Necessita igualmente de abrir-se a uma visibilidade negativa versus uma positiva, que a amplie e questione. $E$, neste contexto, que se redescubram os contornos de uma surpreendente invisibilidade do feminino; se desenvolva um novo olhar sobre a própria visibilidade do feminino na Bíblia e sobretudo que toda a reflexão se abra à dimensão invisível de um agir sábio, que é participação no grande mistério desde logo inscrito na própria criação do ser humano.

Palavras-chave: Visibilidade. Invisibilidade. Feminino. Masculino.

\section{Abstract}

This article seeks to approach the question of the visibility and invisibility of the feminine in the Bible, pursuing the debate of the different nuances that are inherent to it. We seek a truth and a rediscovery of biblical literary strategy that is comprehensive and comprehensive. The debate supposes knowing some previous notes and the fragility of some conventional formulations. It also needs to open up to a negative versus a positive visibility, which expands and questions it.

\footnotetext{
a Universidade Católica Portuguesa (UCP), Lisboa, Portugal. Doutora em Teologia Bíblica pela UCP, e-mail: luisa.almendra@gmail.com
} 
And, it is in this context, that the outlines of a surprising invisibility of the feminine can be rediscovered; develop a new look at the feminine own visibility in the Bible and above all that all reflection is open to the invisible dimension of a wise action, which is participation in the great mystery that is immediately inscribed in the very creation of human beings.

Keywords: Visibility. Invisibility. Female. Male.

\section{Introdução}

O título deste artigo encontra a sua justificação numa intuição de que existe uma visibilidade expressa do feminino na Bíblia que se desenvolve numa interação constante com uma dinâmica de invisibilidade. Se por um lado a presença do feminino é inquestionável, por outro, o modo como os autores bíblicos geriram literariamente esta presença constitui, ainda hoje, um veemente desafio para todos os que procuram uma compreensão precisa e englobante. É por demais conhecida a diversidade de leituras que a presença do feminino no texto bíblico permitiu ao longo de séculos, bem como as consequentes equações e práticas que estas leituras desenvolveram. Numa tentativa de delinear um percurso que nos permita alguma originalidade na nossa abordagem, parece-nos importante ponderarmos uma compreensão do feminino na bíblia com uma perspetiva integradora, onde o feminino e o masculino possam ler-se e entender-se na interação prevista na dinâmica da própria revelação e não como duas realidades a decorrer em paralelo (Gn 1-2). Na verdade, desde a primeira à última página da Bíblia a visibilidade ou invisibilidade do feminino na bíblia desenvolve-se sempre numa dinâmica de interação com o agir masculino. Por isso, na sua visibilidade e invisibilidade queremos oferecer algumas interseções literárias do feminino na Bíblia, sem o isolar do seu habitat natural, que é sempre o de interação com o masculino. Será sempre neste contexto que tentaremos sondar a riqueza literária do dinamismo bíblico do feminino, sublinhando o que se coloca verdadeiramente visível e o que é que se deixa frequentemente invisível (cf. LÓPEZ, 1997; LACOQUE, 1992). 


\section{Algumas constatações prévias}

Uma constatação prévia importante é a de não esquecermos que o tema do feminino na Bíblia foi sempre objeto de uma diversidade de releituras oriundas do mundo judaico e cristão, que, partilhando uma parte da Bíblia, ofereceram sempre releituras muito diversas. É certo que muitas destas releituras também divergem segundo a época em que se situam e foram influenciadas por diversas questões sociais e religiosas de ambos os grupos (cf. BOSETTI, 2013; WÉNIN; FOCANT, 2007). Esta diversidade de leituras motivou e também foi igualmente influenciada pelas inúmeras leituras e interpretações realizadas pela arte em todas as suas vertentes: literatura, cinema, pintura, escultura, música; permitindo que este tema do feminino na Bíblia se tornasse algo que foi sendo prementemente revestido de um imaginário e de uma gramática que tornou muito difícil e dividiu sempre os leitores do texto e os leitores dos intérpretes do texto.

Não obstante, neste âmbito de notas prévias, ocorre evocar a significativa a expressão rabínica: Torah horah (a Escritura é/está grávida). Trata-se de uma expressão sugestiva de uma compreensão da Bíblia, não como um livro apenas repleto de palavras, sufixos ou pronomes no feminino e masculino; mas um livro que na sua essência é semelhante a um útero, que numa indizível intimidade gera os seus leitores para a luz e a vida (cf. WÉNIN; FOCANT, 2007, p. 7). Esta perceção rabínica torna-se relevante, para a nossa apresentação, na medida em que ela questiona vigorosamente uma leitura que muitas vezes se fixa na materialidade da letra, catalogando a Bíblia como um texto que apenas expressa e valoriza o pensamento e a ação masculina, na figura dos seus grandes líderes e heróis (Abraão, Isaac, Jacob, Moisés, David...). Esta perceção rabínica da Torah como um útero não só denuncia estes olhares superficiais como nos desafia a uma atitude nova, onde o essencial é aprender a sondar a interioridade do texto e da palavra, como um lugar onde o masculino e o feminino apelam a uma verdade em Deus que nos surpreenderá constantemente. Neste sentido vislumbrar a visibilidade e a invisibilidade do feminino na Bíblia apresenta-se como um caminho para chegar a esta verdade, que tenderá sempre, de algum modo, a escapar-nos. De qualquer modo, é ponto assente que o feminino na Bíblia é uma realidade bem mais viva e participante do que frequentemente nos parece ou ao que algumas leituras nos possam fazer crer (cf. CHALIER, 2010, p. 7-8). 


\section{Fragilidade das formulações convencionais}

Existe uma ideia amplamente difundida de que, no texto Bíblico, o tempo narrativo confina a expressão do feminino à sombra de um protagonismo masculino, que tende a assumir sempre o controlo das diferentes situações religiosas (Aliança Abraão), sociais (Moisés), políticas (David). No entanto, não são poucas as circunstâncias em que, na Bíblia, as mulheres, a partir dos seus contornos vincadamente femininos, assumem uma liderança, tomando opções que determinam o futuro de um povo ou de um grupo. Um exemplo notável é o de Sifra e Pua (Êx 1,8-16), que ousaram recusar-se obedecer a uma ordem do Faraó, em nome de uma obediência ao Deus da vida. Determinadas e prontas a defender a vida e a existência de um grupo, mostraram uma determinação e inteligência no seu agir, atingindo os seus objetivos sem enredar-se nos impasses da injustiça e da violência (Êx 1,1722). Mas existem muitos outros exemplos: o da juíza e profetiza Débora, a mulher destemida ( $\mathrm{Jz} 4-5$ ), o da rainha Esther que salva o seu povo do genocídio (Et 3-8), o de Rute, a mulher simples de Moab que emerge da obscuridade (Rt 1+-3). Todas elas, são exemplo de tantas outras sublinhadas pela narrativa bíblica como capazes de demonstrar uma audácia inesperada, uma singular capacidade de ponderação. Não só agem e decidem o futuro da sua própria vida, como o do próprio grupo de pertença'.

Neste sentido, podemos afirmar que existe uma significativa fragilidade e superficialidade num entendimento convencional de que na Bíblia existe uma submissão do feminino ao masculino. Se é verdade que estas mulheres não agem isoladamente, e a sua ação revela um interagir numa relação com o masculino, a verdade é que a narrativa bíblica lhes oferece uma visibilidade literária inegável, persistente e atuante. Independentemente, de um agir ou liderança masculina, o texto bíblico dá-lhes uma visibilidade em palavras e gestos femininos inesperados e até mesmo inauditos (cf. CHALIER, 2010, p. 9). Cite-se a título de exemplo as palavras da escrava de Sara, Hagar, que depois da conversa com o mensageiro divino reconhece Deus como "o Deus que me

\footnotetext{
${ }^{1}$ Embora os exemplos oferecidos se situem no âmbito da história de Israel, a narrativa bíblica prolonga esta ousadia e determinação na atenção e cuidado literário que os autores também ofereceram às figuras de Maria de Nazaré, Maria Madalena, Febe, Lídia, Priscila.
} 
vê" (Gn 16,13), tornando-se a primeira mulher que oferece um título a Deus. Algo de semelhante é também visível nas palavras de Ana que, no ato do dom de entregar do seu filho Samuel, elabora a expressão de louvor mais inspiradora da narrativa bíblica ("Exulta o meu coração no Senhor" 1Sm 2,1). Inscrevem-se aqui as palavras incisivas da mulher sirofenícia, que não desiste perante as palavras de um rabi e insiste "Senhor, mas também os cachorrinhos comem das migalhas que caem da mesa dos seus donos" (Mt 15,27); mas também, o pensamento e o gesto da mulher, sem nome, que no seu desespero apenas acredita que bastará tocar o manto de Jesus para ficar curada (Mc 5,28) ou o da mulher que era conhecida como pecadora, e no entanto, não teme colocar-se aos pés de Jesus, lhe regar os pés com as suas lágrimas e os enxugar com os seus cabelos (LC 7,44); palavras e gestos inesperados e inauditos para aquela cultura e ainda em muitas culturas atuais. Neste sentido, o repto é questionarmo-nos o que se tem feito com a visibilidade literária do feminino na Bíblia? Como é que ele tem sido lido e interpretado? Nas inúmeras formulações convencionais que a remeteram para um plano idílico ou que a secundarizaram ao papel do masculino projeta-se uma invisibilidade que anula a riqueza e a vitalidade da própria visibilidade.

\section{Visibilidade negativa versus positiva}

Se de facto a narrativa Bíblica oferece uma visibilidade ao feminino extremamente cuidada e assertiva, a verdade é que o faz contemplando as dimensões positivas e negativas que demarcam a existência humana. Citamos dois dos testemunhos mais veementes. A visibilidade literária negativa que é dada ao comportamento de Dalila, a mulher que trai o seu esposo por prata (Jz 16,4-21), aparece sobrecarregada pelo desconhecimento das suas origens, deixando uma memória de um feminino capaz de destruir impiedosamente um homem poderoso. A visibilidade do poder negativo do feminino emerge num contraste literário com a descrição da visibilidade masculina de Sansão, que era fisicamente forte, mas moralmente fraco. Embora capaz de rasgar um leão, não conseguiu lutar contra suas luxúrias. Conseguiu conquistar os filisteus, mas não suas paixões. Numa oposição de forças e fraqueza, de uma visibilidade feminina e masculina, Dalila vence como uma mulher que soube 
usar seu charme pessoal para atrair um homem forte à sua destruição espiritual e física. A narrativa e as suas releituras sucessivas abandonaram-na a uma visibilidade negativa do feminino onde ela se destaca como uma das mulheres mais humildes e mesquinhas da Bíblia. ${ }^{2}$

Um segundo exemplo emerge na visibilidade literária que é dada a Jezabel, conhecida como a mulher demoníaca (1Rs 16,31; 18,4-19; 19,1-2; 5-25; 2Rs 9). Num contraste com o significado do seu nome - mulher casta - a narrativa oferece-lhe uma visibilidade com contornos muito particulares: se por um lado a descreve como uma mulher sem coração com uma história sangrenta, por outro ela é por natureza uma mulher silenciosa, pagã que casa com o rei Acab, rei do Norte de Israel. As suas origens pagãs e o seu carácter ambicioso e perverso dominam a visibilidade que a narrativa que lhe dá. Cativado por Jezabel, Acab não só desposa Jezabel como passa a servir as suas divindades, tornando o maior dos seus erros (1Rs 16,31; Mq 6,16). A força da visibilidade da figura feminina de Jezabel domina a narrativa bíblica e sublinha e as consequências negativas da idolatria que significou para Israel mais do que quebrar os dois primeiros mandamentos da lei; produziu desintegração espiritual e moral que foi acentuada pelo esforço determinado de Jezabel para destruir a adoração a Yhwh. Numa interação entre a visibilidade feminina e masculina, a narrativa bíblica submete à figura masculina de Acab o caráter de Jezabel - um nome que passou a significar em todas as épocas a imagem impressionante do poder sedutor, sutileza mundana e maldade do pior tipo. No entanto, não obstante, investida pela sua extraordinária força de caráter, a narrativa atribui-Ihe um terrível destino, com uma grandeza trágica inigualável a qualquer outra mulher da Bíblia. Embora a visibilidade que a narrativa Bíblia Ihe dá não analise ou mesmo retrate seu caráter, mas simplesmente apresente os eventos nos quais ela teve um papel proeminente, ainda assim, nas entrelinhas, não podemos deixar de vê-la como uma mulher de força prodigiosa de intelecto e vontade. A narrativa não registra que ela possuísse qualquer uma das qualidades femininas mais refinadas e nobres. Selvagem e implacável, era mulher orgulhosa e obstinada que soube executar os seus

\footnotetext{
${ }^{2}$ Curiosamente, esta traição feminina aparece relida, na traição de Judas, uma figura masculina, que domina a narrativa final sobre a vida terena de Jesus.
} 
planos infames. Uma mulher talentosa na promoção do mal. Persuasiva e decidida, usou sua força de caráter para destruir um rei e sua própria descendência. É na sequência desta visibilidade negativa do feminino que devem entender-se expressões como as de Ec 7,26 (... e descobri que a mulher é mais amarga do que a morte, pois é uma armadilha).

Esta visibilidade positiva e negativa foi sempre de tal modo significativa para a cultura ocidental que foi inspiradora de uma galeria de imagens femininas inigualável em toda a literatura. A vida destas mulheres, na diversidade e singularidade do seu destino e da influência que a história da sua vida exerceu tornaram-nas únicas. E se elas continuam a povoar o imaginário literário e existencial, não é meramente porque elas aparecem na Bíblia, é porque são testemunho de humanidade real. Não são seres mitológicos, são mulheres reais, que viveram numa história real e a assumiram de uma forma humana que ainda hoje nos desafia, no que ela teve de positivo ou de negativo.

\section{A surpreendente invisibilidade do feminino}

Contudo, a par de uma visibilidade real e verdadeira, existe uma invisibilidade desconcertante do feminino. Esta invisibilidade transparece nas narrativas que procuram sublinhar sobretudo a exterioridade da ação, mais do que a força interior que a move e sustém. Um exemplo significativo é o caso de Ester, em que a narrativa insiste em submeter a sua determinação em salvar o seu povo à sua beleza (Et 2,15s), criando a impressão de que se Ester não fosse uma mulher de uma beleza singular, nunca teria podido agir com a convicção e determinação com que o fez ${ }^{3}$. Este fenómeno da invisibilidade ocorre, também, na frequência com que o feminino, não obstante relevante na narrativa, é deixado num inexplicável anonimato. Os exemplos são

\footnotetext{
${ }^{3}$ Este jogo narrativo transparece nos nomes e nos significados que narrativa atribui a Ester. Enquanto um nome de origem persa, inspirado no termo "aster", que significa "estrela", implicando, como Vênus, "boa sorte"; ou inspirado no termo "sether", que significa "se esconder", porque ela estava escondida na casa de seu tutor e porque sua nacionalidade estava oculta (Est 2,7). Ambos constituem uma tentativa de substituição do nome Hadassah, que procura indicar a verdadeira beleza pela qual Ester outrora cativa; é agora uma rainha persa, famosa, pelo seu julgamento claro, a sua capacidade de autocontrole do mais nobre autossacrifício.
} 
inúmeros e emergem desde muito cedo na narrativa bíblica: insiste-se nos nomes dos filhos de Noé, mas nunca se alude ao da sua esposa ou da sua nora (Gn 6,10; 7,13); fala-se de Lot, mas mantém-se um silêncio inexplicável em relação aos nomes de sua esposa e duas filhas (Gn 19,15-26). Na construção do Tabernáculo, fala-se de homens, como os sábios Bezaleel e Aoliabe foram autorizados por Deus para o trabalho da construção, mas também do papel que as mulheres também desempenharam (35,22-29; 36,1-3). A narrativa define-as igualmente como sábias de coração que fiavam com as mãos, e traziam o que tinham fiado, tanto de azul como de púrpura, e de carmesim, e de linho fino (35,25-26); mulheres hábeis no manejo do fuso, com corações dispostos trabalharam como para o Senhor, porém omite o seu nome, deixando-as num anonimato estranho ${ }^{4}$. Igualmente surpreendente será sempre o anonimato da filha de Jefté, a mulher sacrificada por um voto ( $\mathrm{Jz}$ 11,30-39). Embora a narrativa não faça qualquer alusão à sua esposa, tem o cuidado de expressar a afeição que Jefté tinha pela sua única filha, que ele nunca esperava ser a primeira pessoa que viesse ao seu encontro no regresso da sua vitória. A narrativa deixa no invisível o seu nome e a execução final do voto, sublinhando apenas a sua extraordinária aceitação de que ela seria a oferta queimada que seu pai havia prometido. Conhecida apenas pelo título simples de "filha de Jefté", a narrativa omite o nome, mas oferece uma visibilidade extraordinária à sua obediência, revelando os traços femininos de uma nobreza de caráter que a narrativa conserva, independentemente de todas as releituras que sobre o caso possam ser feitas. Não existe uma resposta satisfatória para o silêncio que a narrativa faz sobre a identidade destas mulheres. Seja como for, no facto de se assinalar a sua presença feminina, elas mantêm algo de imortalidade e constituem esboços vivos de um feminino que será, não pelo nome, mas pela sua ação.

\footnotetext{
${ }^{4}$ Este anonimato parece recuperar-se na referência explícita a Dorcas que assume, nos tempos do cristianismo, o papel destas mulheres sábias de antigamente que serviam a Deus com suas agulhas e linha.
} 


\section{Novo olhar sobre visibilidade do feminino}

Entre a multiplicidade de estudos que tentaram uma abordagem desta temática situam-se os estudos de Catherine Chalier. Nos seus estudos encontramos bem expressa a recusa de todas as formas de encarcerar a visibilidade do feminino na Bíblia ao espaço interior da casa, da intriga amorosa, ou até mesmo do eterno feminino. A sua proposta desafia-nos à perceção de um feminino pleno, que a Bíblia torna visível na capacidade singular que o feminino demonstra de saber existir não para si, mas para o outro, seja ele um parceiro masculino ou o povo no seu conjunto; uma quase inabarcável capacidade de amar. ${ }^{5}$. É neste sentido que Catherine Chalier avalia as grandes matriarcas de Israel: Sara, Rebeca, Raquel e Lea, que na fragilidade e na força da sua existência desempenharam num papel crucial numa História de Israel. Ninguém como elas soube vigiar a realização de uma Aliança entre Deus e o seu povo e ninguém como elas nos obriga a pensar no pleno sentido desta Aliança entre Deus e a humanidade. O seu ser e o seu agir demarcam-se e releem-se nas entrelinhas da sua vida, das suas escolhas e dos seus compromissos. Por isso, compreendemos que Catherine Chalier defenda a que, para compreendermos a visibilidade do feminino na Bíblia, não basta sublinhar o ser de mulher, de mãe, ou de esposa, mas de apreender como e porquê estas e outras mulheres foram escolhidas para assumir a imensurável responsabilidade de resguardar uma Aliança, que é dom e fundamento da relação entre Deus e a humanidade (cf. CHALIER, 2010, p. 14; MURPHYO'CONNER; MILITELLO; RIGATO, 2006).

Nesta linha de pensamento ocorre situar, também, o contributo importante de Irmtraud Fischer. Num dos seus estudos publicado sob o nome Des femmes aux prises avec Dieu, ela não teme afirmar e demonstrar o modo como as mulheres fundadoras do povo de Israel e da dinastia davídica integram uma compreensão da história das origens de Israel que respeita a dualidade sexual (cf. FISCHER, 2008a). Sara é com Abraão parte integrante na realização da promessa (Gn 12-23); Rebeca é a mulher forte que decide e

\footnotetext{
${ }^{5}$ Cf. CHALIER, 1982 : «Les mères d'Israël dans leur féminité seraient l'avènement même dans l'être de cette responsabilité, ou, du moins déjà rupture de l'être par cette bonté...».
} 
protege o seu esposo Isaac (Gn 24-28); Raquel e Lea, as duas grandes fundadoras da casa de Israel, são o motivo pelo qual Jacob serve Labão duas vezes 7 anos, e para que a promessa perdure as duas lutam com Deus pelo amor do seu esposo e a fertilidade do seu ventre (Gn 29-32). O contributo de Irmtraud Fischer prolonga-se no seu interesse pelo papel relevante das mulheres profetas e no conceito de profecia que lhes corresponde. Este interesse expande-se numa pesquisa, onde a visibilidade do feminino na Bíblia se realiza pelo agir sábio (cf. FISCHER, 2008b; FISCHER, 2008c). Situa-se neste âmbito o agir sábio de mulheres como Abigail. A sua força de espírito e o seu brilhante bom senso sobrepõem-se perante a fragilidade moral do seu esposo (1Sm 25,3) (cf. FISCHER, 2004, p. 154-160, 186-198). Ao contrário do seu esposo, Nabal, Abigail sabe se comportar e dirigir àquele de quem a sua prosperidade e toda a sua casa dependem (David). Magnânima na gestão dos seus bens, a sua mão não é como a do seu marido, não faz presentes, dá o que é necessário e ainda o supérfluo; sabe julgar com justiça e deixar-se instruir por quem não o é (1Sm 25,23-35). Podemos ainda evocar a mulher prevenida de Téqoa; uma mulher inteligente, chamada a uma missão delicada (2Sm 14); a mulher sábia de Abel-bet-Maaka, dotada de uma inteligência pacificadora (2Sm 20,13-22); a rainha de Saba, uma das mulheres sábias mais conhecidas do AT, que não teme colocar à prova a sabedoria do grande rei sábio Salomão (1Rs 10,1-10).

\section{A invisibilidade do agir sábio}

Estas mulheres dotadas de um agir sábio não estão sós. A visibilidade do feminino na Bíblia é suficientemente ampla e rica para abrigar um grupo significativo de mulheres que souberam viver em função de uma sabedoria de conselho. Estão entre elas Judite e Débora, autênticas mestras da Torah (Jz 4,4-10; Jud 11,5-7; Est 7,1-10). Na maioria dos casos, o conselho destas mulheres foi considerado como digno de atenção por aqueles que as escutaram. Porém, existem alguns casos em que o conselho de algumas mulheres aparece como enigmático, como o da mulher de Job que como ele recebe as notícias do desastre que assombra a sua casa e a sua família e aconselha Job a bendizer / 
maldizer a Deus e a morrer (Jó 2,9) (cf. FISCHER, 2008b, p. 111-123) ${ }^{6}$. É neste contexto narrativo de sabedoria que a expressão do feminino na Bíblia atinge um vértice inesperado na figuração feminina da sabedoria. Basta nos abrirmos à leitura de algumas páginas do Livro dos Provérbios, Ben Sira e Sabedoria para vermos de imediato erguer-se a visibilidade de um rosto que nos surpreende pelos seus inúmeros traços femininos. A sabedoria assume a figuração de uma mulher, descrita como uma jovem, uma irmã, uma mãe, uma educadora e guia, companheira noiva e esposa.

Eu a amei e busquei desde a minha juventude, procurei tomá-la por esposa e enamorei-me da sua formosura... Por isso resolvi tomá-la por companheira da minha vida sabendo que ela será para mim conselheira do bem e consolo nas preocupações e nas tristezas (Sb 8,2) Diz à sabedoria: «Tu és minha irmã» e chama à inteligência tua parente. ( $\operatorname{Pr} 7,4)$; Não abandones a sabedoria e ela te guardará, ama-a e ela te protegerá...Tem-na em grande estima e ela te exaltará, glorificar-te-á se a abraçares. ( $\operatorname{Pr} 4,6.8$ ); Assim faz aquele que teme o Senhor; o que se dedica à lei possuirá a sabedoria. Ela virá ao seu encontro como uma mãe e o acolherá como uma esposa virgem. (Sir 15,1-2).

Juntam-se a estes textos muitos outros onde a sabedoria aparece visível na mulher que clama nas ruas, eleva a sua voz nas praças, grita por sobre os muros, faz ouvir a sua voz à entrada das portas da cidade ( $\operatorname{Pr} 1,20-21)$, falando de si e convidando a uma procura semelhante à do amado e da amada do Livro do Cântico dos Cânticos

Feliz aquele que se aplica à sabedoria... vai atrás dela como quem the segue o rasto e permanece nos seus caminhos, olha pela janela a sabedoria e escuta às suas portas; detém-se junto da sua morada e fixa um prego nas suas paredes; levanta a sua tenda junto dela e estabelece ali agradável morada. (Sir 14, 20.2225); vou levantar-me e dar voltas pela cidade, pelas praças e pelas ruas, procurarei aquele que o meu coração ama. (Ct 3,2) Cresci como a palmeira de Ein-guedi, como roseiras de Jericó, como uma formosa oliveira na planície, cresci como plátano... (Sir 24,14); és um jardim fechado, minha irmã e minha esposa... os teus rebentos são um pomar de romãzeiras com frutos deliciosos, com

\footnotetext{
${ }^{6} \mathrm{E}$ não podemos esquecer aqui o conselho ambíguo das mulheres que são incapazes de estabelecer uma distância em relação aos seus desejos. É o caso de Zarés, esposa de Aman, que cega pela sua ambição julga insuportável que alguém ouse recusar render honra ao seu esposo (Et 5-6); de Atalia a mãe que aconselha o filho a fazer o mal (2Cr 22,2-5); ou, ainda, de Jezabel, esposa de Acab, que sob o seu conselho e ordem obriga os anciãos e notáveis da cidade a matar Nabot para poder tomar a sua vinha, que o seu esposo tanto desejara (1Rs 21,8-16).
} 
alfenas e nardos, nardo e açafrão, cálamo e canela, com toda a espécie de árvores de incenso, mirra e aloés. (Ct 4,12-14)

\section{Invisibilidade participante no mistério}

Anne-Marie Pelletier (1995, p. 197-207), autora de dois estudos significativos, "O cristianismo e as mulheres - Vinte séculos de história" e "O sinal da mulher", fala-nos de uma visibilidade do feminino, na sabedoria bíblica, como um traço profético, onde o mistério clarifica progressivamente o seu caminho. Na interioridade misteriosamente geradora de vida, que corre nas veias das simples imagens femininas de irmã, mãe, amiga, mulher, afiança-se a presença de um feminino que precede o ser humano, na sua forma de homem ou mulher; um feminino que não interfere com a diferença de sexos, tal como ele emerge na tradição bíblica com criação do homem e da mulher, mas antes a excede de um modo único e arrebatador. Os autores do Novo Testamento quiseram reafirmar esta visibilidade do feminino da sabedoria bíblica numa figuração feminina da Igreja, tal como o Livro do Apocalipse a descreve (Ap 12 e 21). No fim dos tempos, será de novo "Ela", como um sinal do céu, quem destruirá as forças do mal (Ap 12,1); que se opondo à grande prostituta, assumirá a figura de uma "noiva adornada para o seu esposo" (Ap 21,2). 0 feminino que estava junto de Deus na criação $(\operatorname{Pr} 8)$ estará de novo no fim dos tempos; os tempos da nova criação, do novo céu e da nova terra (Ap 21,1-4); o tempo de Cristo, que Paulo descreve como o tempo em que «... não há judeu nem grego; não há servo nem livre; não há macho nem fêmea; porque todos

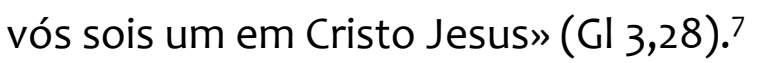

\section{Conclusão}

A verdade é que na Bíblia, o feminino e o masculino nunca são apenas uma realidade física. Na Bíblia, o humano e o divino estão sob um horizonte de

\footnotetext{
${ }^{7}$ Esta inesperada e solene referência ao feminino no último livro da Bíblia assume uma importância notável, principalmente se recordarmos a circunspeção com que os textos sinópticos se referem aos "últimos tempos", falando apenas de um tempo em que o homem e a mulher não se tomarão um ao outro (Mt 22,23-33; Mc 12,18-27; Lc 20,27-40); (cf. MURPHY-O'CONNER; MILITELLO; RIGATO, 2006).
} 
revelação, e sob de uma plenitude que os atinge no âmago, no coração do coração. No interior de uma Sara que sai da sua terra com Abrão, inaugura-se um caminho de risco e de fadiga que não se sabe onde levará. É um caminho que a leva para fora e para dentro; um caminho que a leva a se tornar plenamente aquilo que é: mulher de Abrão e lugar de realização da promessa $($ Gn 12,1). Ela será o grande paradigma de um feminino que estará sempre no caminho de realização da promessa e da salvação. Depois dela, a narrativa bíblica e a História da salvação insistem na persistência de um caminhar feminino (cf. BOSETTI, 2010). Miriam, a profetiza do êxodo, guia o povo pelo caminho do deserto com Moisés (Êx 15,20-21). Noémi reencontra com Rute, a sua nora, no caminho de regresso a Judá (Rt 1,1-22). A mulher enamorada do Cântico dos Cânticos desafia os caminhos sinuosos do deserto para procurar o amado (Ct 3,6). Maria de Nazaré fia-se nas palavras do anjo e coloca-se de imediato a caminho, dirigindo-se apressadamente a uma cidade de Judá (LC 1,39). Maria, chamada Madalena, Joana, a mulher de Cuza, Suzana e várias outras, seguiam Jesus nos caminhos da sua pregação (Lc 8,1-3). Febe, Prisca e Júnia estão entre as muitas mulheres que Paulo cita e reconhece no seu infatigável e generoso contributo nos caminhos percorridos no anúncio da Palavra do Evangelho (Rm 16,1-16). Tal como Sara este caminhar move-se e sustém-se numa realidade maior que é a plenitude do ser e de um desígnio de vida de Deus no humano: algo que os autores bíblicos souberam apenas balbuciar nas palavras: Deus criou 'adam à sua imagem, à imagem de Deus ele o criou, homem e mulher ele o criou (Gn 1,27).

\section{Referências}

BOSETTI, E. Donne della Bibbia: Bellezza intrighi, fede, passione. Assiri: Cittadella Editrice, 2013.

CHALIER, C. Figures du féminin: Lecture d'Emmanuel Lévinas, La nuit surveillée. Paris: Verdier, 1982.

CHALIER, C. Les matriarches : Sarah, Rebecca, Rachel et Léa. Paris: Éditions Cerf, 2010. FISCHER, I. Des femmes aux prises avec Dieu : Récits bibliques sur les débuts d'Israël. Paris: Cerf, 2008a. 
FISCHER, I. Des femmes messagères de Dieu : Prophètes et prophétesses dans la Bible hébraïque. Pour une interprétation respectueuse de la dualité sexuelle. Paris: Cerf, 2008b.

FISCHER, I. Femmes sages et dame Sagesse dans l'Ancien Testament: Des femmes conseillères et éducatrices au nom de Dieu. Paris: Cerf, 2008c.

FISCHER, I. Gender-faire Exegese: Gesammelte Beiträge zur Reflexion des Genderbias und seiner Auswirkungen in der Übersetzung und Auslegung von biblischen Texten. Münster: Lit, 2004.

LACOQUE, A. Subversives : Un Pentateuque de femmes. Paris: Editions Cerf, 1992.

LÓPEZ, E. E. Práticas compassivas y visibilidade femenina. In: PUERTO, M. N. La mujer en la Biblia. Navarra: Editorial Verbo Divino, 1997. p. 23-34.

MURPhY-O'CONNER, J.; MILITEllo, C.; RIGATO, M. L. Paolo e le donne. Assiti: Cittadella Editrice, 2006.

PELLETIER, A-M. La Sagesse au féminin dans la Bible. Un repérage de la question. In: CONGRÈS DE L'ACFEB. LA SAGESSE BIBLIQUE DE L'ANCIEN AU NOUVEAU TESTAMENT, 15., 1995, Paris. Actes... Paris, 1995. p. 197-207.

WÉNIN, A.; FOCANT, C. Vives femmes de la Bible. Bruxelas: Éditions Lessius, 2007. 